\title{
No place to pump
}

Cite as: CMAJ 2020 March 2;192:E225-6. doi: 10.1503/cmaj.1095850

Posted on cmajnews.com on February 14, 2020

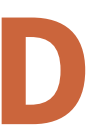

r. Miriam Mottiar, an Ottawabased anesthesiologist, returned to work when her second child was five months old. For the first week, she tried to pump breastmilk between cases, but it wasn't always possible. "My milk supply was decreasing. It was hard for me; it was hard for my baby," she says.

So, she spoke to her department head, Dr. Colin McCartney, about pumping in the operating room. He gave her the go-ahead. "He was a real ally," says Mottiar. She used a hands-free system and wore an operating room jacket backwards to cover it.

When nurses questioned whether her pumping posed a sterility concern, Mottiar met with hospital leaders, which resulted in a memo signed by two department heads and a vice president. "While there is no evidence base to guide decisions in this area, in discussion with the Medical Director of Infection Prevention and Control ... we believe that when carried out with proper precautions, pumping in the operating room poses little risk to patients," the memo read.

That seemed to settle the issue, until one day a surgeon asked about the sound of the pump, which he hadn't noticed before over the hum of the operating room. When Mottiar explained she was pumping, he replied, "That's disgusting."

"I felt so vulnerable in the moment," Mottiar recounts. "And of course, I cried."

Mottiar's experience is not unusual, according to Dr. Michelle Cohen, advocacy chair at Canadian Women In Medicine. She recently surveyed doctors about their experiences pumping during residency.

"Many people have that attitude that it should be secret, that it's dirty, or that you're not a devoted doctor if you're taking time away to do this," she says. One survey respondent reported that her preceptor wrote "the resident frequently

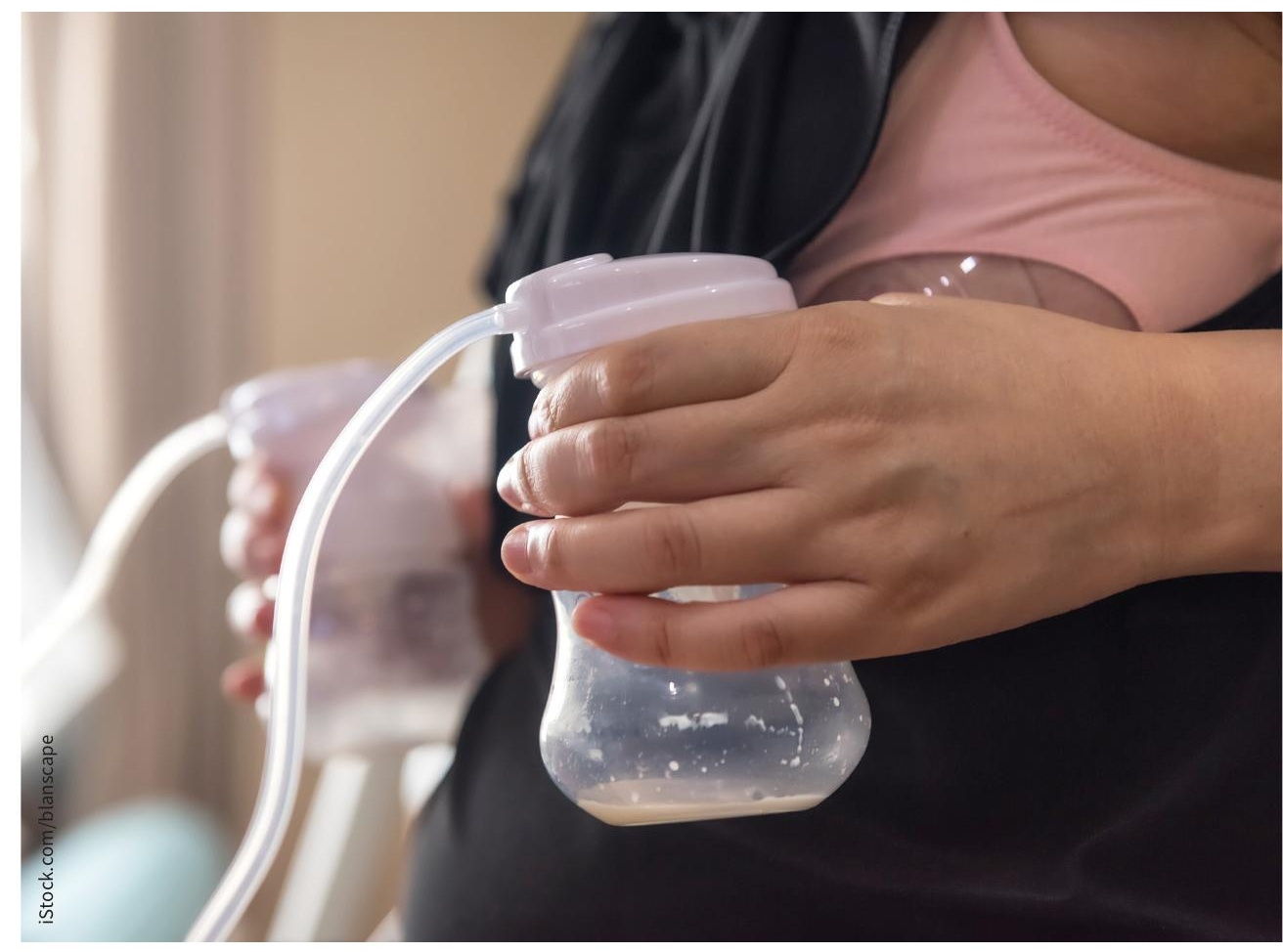

Doctors encourage their patients to breastfeed but have limited workplace accommodations to do so themselves.

took breaks from clinical work to feed her child" under the "needs improvement" section of her evaluation.

Given these attitudes, it's unsurprising that workplace accommodations for physicians who breastfeed are dismal. In Cohen's survey of 170 physicians, $68 \%$ reported not having had adequate time and nearly $73 \%$ felt they didn't have adequate space to pump at work. Storage is another issue, with $63 \%$ of doctors saying they didn't have somewhere to store pumped breastmilk. "It's treated as a biohazard, which it's not," says Cohen. "It's a food product."

The Ontario Human Rights Commission states that employers have a "duty to accommodate" women who need to breastfeed or pump milk at work. But Cohen notes that the human rights language is "deliberately broad" and workplace policies are needed to detail the specifics of the accommodation.

It's a health concern as well as a human rights issue, given the multiple health benefits of breastfeeding for both infants and mothers. For working mothers who wish to continue breastfeeding, regular pumping is also necessary to maintain milk supply and avoid health issues such as mastitis.

Canadian Women In Medicine wants residency programs and health organizations to create lactation accommodation policies, for example, to require the provision of pumping spaces. 
Dr. Franco Rizzuti, president of the Professional Association of Resident Physicians of Alberta, says the organization supports trainees who are pumping by advocating for them on a "case by case" basis. When it comes to the collective agreement for residents in the province, breastfeeding accommodations are "something we're working on actively," he says, but progress depends on "what the universities and Alberta Health Services are able to put in place."

Dr. Anthea Lafreniere, president of the Professional Association of Residents of Ontario, says the organization is updating its frequently asked questions on breastfeeding with contacts at each site who are responsible for helping residents find a place to pump and store breastmilk. In addition, the organization will intervene whenever residents flag barriers to breastfeeding. "We have been successful in finding options for every case of a member who has come to us," she says.

But Cohen says accommodations should be guaranteed proactively under collective agreements, instead of being negotiated individually. By the time accommodations are sorted out on an individual basis, a physician's milk supply can be compromised, she explains.

\section{Signs of change}

Sixteen years ago, when Calgary obstetrician and gynecologist Dr. Fiona Mattatal returned to her residency program after the birth of her first child, she didn't tell anyone she needed to pump, but snuck in breaks to pump when she could. "I'd try to rest my pump on the toilet paper roll," she recalls.
Nine years later, after the birth of another child, she had access to a call room to pump, but worried colleagues would walk in, and five-hour surgeries made pumping impossible some days. In both cases, she stopped pumping after a few weeks.

But Mattatal says attitudes about breastfeeding at work are changing. Now, she and her colleagues knock on the staff room door before entering, in case someone is using the room to pump. And both her male and female colleagues back up physicians who need to take pumping breaks. "They're like, 'You go ahead, I'll carry a pager for half an hour.'”

Cohen says much depends on the culture of a workplace. "There are some places that are quite welcoming and support it. It varies a lot."

Normalizing pumping with policies and facilities is one way to change the culture, she adds. And that's what at least one medical school and two hospitals in Canada are doing.

The Northern Ontario School of Medicine is in the process of passing a lactation accommodations policy for all medical students and residents. It requires the provision of 20-minute pumping breaks every four hours, in addition to meals and other breaks, and a clean, "nonbathroom" private space with a sink. The policy also addresses storage, stating that breastmilk can be stored in fridges used by staff for food.

The policy was spearheaded by Kaitlin Gonzalez, a third-year medical student at the school, and is fully supported by school leadership. "It's 2020, not 1920," says Dean Dr. Sarita Verma. "Why are we still running into these issues?"
Verma adds that she is happy to share the policy with other schools. "We've done a lot of soul searching and consultations with our people about this."

In Calgary, Foothills Medical Centre recently opened a breastfeeding and pumping room for staff, physicians, and volunteers, in response to advocacy from physicians. "We picked the location because it's centrally located and if a partner is bringing a baby specifically for this purpose, it allows them to do that without having to take the baby through clinically sensitive areas and risk infection," says Dr. Peter Jamieson, medical director of the hospital. "In my mind, it's an essential part of contributing to the wellness of physicians and their families."

He says that departments are working out ways to provide pumping breaks. "We have several female emergency physicians who are returning to work, and it's hard to interrupt shifts, but the department is doing what they can to make sure that that is feasible."

The Ottawa Hospital also has a lactation room for physicians and staff, which opened last fall, after more than a year of advocacy from Mottiar and her colleagues.

But neither the Calgary nor the Ottawa lactation rooms have a fridge. At the Ottawa Hospital, security expressed concern about people coming into the room, which requires a card entry, and "potentially tampering with the milk or stealing it," says Mottiar. Others in infection control worried about bacterial cross-contamination. The fridge, she says, "is a work in progress."

Wendy Glauser, Toronto, Ont. 